\title{
Recordando a Maruja Boga. La voz de la emigración gallega en la radiofonía argentina
}

\author{
Teresa PiÑEIRO-OTERo \\ Universidade da Coruña \\ teresa.pineiro@udc.es \\ María de la Encina GARcÍA-COFRADES \\ Universidad de Jaén \\ ency-17@hotmail.com
}

Recibido: 30 de mayo de 2016

Aceptado: 8 de septiembre de 2016

\section{Resumen}

El fenómeno de la emigración gallega a América conllevó la aparición de una Galicia en ultramar. El peso y dinamismo de esta emigración en las sociedades de acogida, especialmente en la Argentina, favoreció la aparición de numerosas publicaciones y programas radiales que trataron los intereses de la colectividad y reforzaron su vínculo con Galicia. Entre ellas destaca Recordando a Galicia (Buenos Aires, 1945-1984) una audición cultural que supuso un alegato del galeguismo con el que su directora, Maruja Boga, estaba comprometida. A pesar de que su voz pervive en la memoria colectiva de la emigración, Boga no ha recibido la atención de otros comunicadores de la Galicia ultramar.

Palabras clave: Radio; emigración gallega; medios de comunicación; América; Argentina.

\section{Remembering Maruja Boga. The voice of the Galician emigration in Argentina radiophony}

\begin{abstract}
The phenomenon of the Galician emigration to America led to the emergence of Galicia overseas. The weight and dynamism of this migration in host societies, especially in Argentina, favoured the apparition of numerous publications and radio programs that treated the interests of the collectivity and reinforced its bond with Galicia. Highly remarkable is the radio program "Recordando Galicia" ("Remembering Galicia", Buenos Aires, 1945-1984) a cultural hearing that became a plea of galeguism that her director, Maruja Boga, was compromised with. Although her voice lives on in the collective memory of emigration, Boga has not received the attention of other personalities, nor in Galicia neither overseas.
\end{abstract}

Keywords: Radio; Galician emigration; Media; America; Argentina.

\section{Referencia normalizada}

Piñeiro-Otero, T. y Encina García-Cofrades, $M^{\text {a }}$ de la (2016). Recordando a Maruja Boga. La voz de la emigración gallega en la radiofonía argentina. Historia y Comunicación Social. Vol 21, número 2, páginas 541-563. 
Sumario: 1. Introducción. 2. Una breve aproximación a la prensa de emigración. 3. Las audiciones históricas de la emigración gallega en América. 4. Materiales y métodos. 5. Maruja Boga, una personalidad polifacética y comprometida. 6. Algo más que una voz. Boga en Recordando a Galicia. 7. A modo de conclusión. 8. Referencias bibliográficas.

\section{Introducción ${ }^{1}$}

Si combinamos la capacidad dinámica de la Galicia emigrada con el potencial de Galicia territorial, llegaremos a un vigoroso y pleno desarrollo de nuestra personalidad colectiva.

Con estas palabras el intelectual gallego Ramón Otero Pedrayo (en Neira Vilas, 2001: 20) subrayaba la esencia dual de Galicia en el histórico Congreso de la Emigración Gallega, celebrado en Buenos Aires en 1956.

Galicia ha sido un país estructuralmente emigrante (Rey Castelao, 2013). Antes del inicio de la emigración masiva hacia América y Europa existieron migraciones intrapeninsulares hacia Castilla, Andalucía y Portugal (Eiras Roel, 1991).

En cuanto a la emigración a ultramar si bien se registraron desplazamientos previos multitudinarios, como la expedición de las familias ${ }^{2}$, ésta no alcanzó gran entidad hasta el siglo XIX. Desde el final del Antiguo Régimen el desplazamiento de gallegos a América fue in crescendo hasta convertirse en un fenómeno masivo, especialmente tras la Real Orden del 30 de enero de 1873 que puso fin a la política restrictiva de la Corona con la emigración (Castiñeira y Martín, 1999:182; López Conde, 1994:61)33.

El primer destino de esta emigración fue Cuba mas a finales de la década de los 80 (s.XIX) comenzó a intensificarse el tráfico hacia los países rioplatenses, alcanzando su culmen en las primeras décadas del siglo XX (Samuelle Lamela, 2000: 40).

Para los españoles Argentina constituyó una segunda patria, consolidándose como el destino por antonomasia de la emigración gallega. En efecto, de los 2.070 .874 de españoles que arribaron al país porteño entre 1857 y 1930, en torno a un 55\% había nacido en Galicia (Farías, 2007:18).

La magnitud de este fenómeno y su concentración en los principales núcleos urbanos propició un hecho curioso: durante la primera mitad del siglo XX Buenos Aires fue la ciudad gallega más grande del mundo (Farías 2007: 2011)4.

Con el retorno siempre presente la colectividad gallega en Argentina desplegó una importante labor asociacionista que permitió el desarrollo de numerosas actividades tanto de carácter festivo como cultural y político (Roca, 2011; Farías, 2011). Más allá de su estructura y objetivos, las diversas entidades gallegas constituyeron redes sociales que permitieron estrechar lazos, aportar el marco de referencia preciso para la construcción de la identidad gallega y fomentar el sentimiento de pertenencia.

Como señaló Neira Vilas (2001) fue en la ciudad porteña donde muchos emigrantes gallegos tomaron consciencia, por vez primera, de su propia identidad. De hecho, 
cruzar fronteras afecta profundamente el modo de entender las afiliaciones y los estados nacionales (Westowood y Phizaclea, 2000).

Más que una ciudadanía propiamente dicha los gallegos han conformado una comunidad simbólica, portadora de un sentido de identidad y alianza, incluso entre individuos que no han tenido contacto con la nación de origen. Porque, como recogió Maruja Boga en un editorial de la audición Recordando a Galicia: "Ser gallego no significa simplemente haber nacido en Galicia" 5.

La denominación de Argentina como "quinta provincia" presenta una vertiente simbólica, que reconoce la identidad del pueblo gallego con independencia del territorio que ocupen, pero también una realidad: una parte importante de las manifestaciones culturales y políticas de la Galicia del siglo XX se produjo en la diáspora.

Muchos, además de ganarnos el pan de cada día, estudiábamos por las noches y, además, en contacto con los paisanos más lúcidos y combativos, descubrimos Galicia, y desde entonces trabajamos con legítimo entusiasmo por la dignificación de nuestro país de origen. Lo asumíamos como algo ineludible. Como una mística. Los que no participaban dictando conferencias, o asistiendo a ellas, hablando de Galicia por la radio, o editando libros, pongo por ejemplo, lo hacían asociándose a entidades comarcales o provinciales a donde pertenecían, haciendo su aporte para cualquier obra de bien común o bailando los domingos por la tarde en algún centro recreativo de la colectividad. Cada quien evocaba a su manera la tierra dejada, con una clara disposición asociativa y solidaria (Neira Vilas 2001:18).

La importancia de la emigración de Galicia a América, su continuidad en el tiempo, y la permanencia de los gallegos en las sociedades de acogida favoreció el surgimiento de sus propios medios de comunicación bien en el seno de las sociedades y centros gallegos, bien de iniciativas privadas. Estas estructuras comunicativas permitieron a los emigrantes mantener el vínculo con Galicia y continuar participando de la vida política, económica, cultural o festivo-religiosa de la comunidad aún fuera de ésta (Pérez y Pérez, 2009).

Precisamente, el interés de la emigración gallega por los acontecimientos de la Galicia territorial llevó a la primera retransmisión transoceánica entre España y Argentina. El 18 de diciembre Radio Splendid (una de las principales emisoras bonaerenses) efectuó una retransmisión desde Santiago de Compostela para informar en directo a la comunidad gallega en Argentina sobre la Asamblea de Concellos que trató el primer Estatuto de Autonomía de Galicia (Blanco Campaña, 1999). ${ }^{6}$

Esta conexión radiofónica se adelantó a la primera emisora gallega, EAJ-4 Radio Galicia, que iniciaría sus retransmisiones apenas un mes después.

En esta línea el estudio de la historia de la prensa y radio gallegas, así como de sus profesionales, hace precisa una aproximación a la otra Galicia. Medios y comunicadores de la emigración y -posteriormente- del exilio detentan un peso relevante en la historia de la comunicación gallega adelantándose en múltiples ocasiones a sus homólogos de la Galicia territorial. 


\section{Una breve aproximación a la prensa de la emigración}

Hablar de la prensa de la emigración es hacerlo de un conjunto heterogéneo de publicaciones periódicas editadas por los gallegos fuera de Galicia (Pérez Pais, 1986: 162). Bajo esta denominación se incluyen boletines de las sociedades y centros gallegos; revistas con noticias de Galicia y otras informaciones de la colectividad; publicaciones puramente literarias; prensa difusora del ideario galeguista o revistas con contenido político y partidario (Blanco Campaña, 1995:89).

El surgimiento de la prensa de la emigración debe situarse en América en los años 70 del siglo XIX y más concretamente en Cuba, país de destino de las primeras oleadas migratorias (Neira Vilas, 1985; Pérez Pais, 1986; Blanco Campaña, 1995).

La primera cabecera de este tipo fue La gaita gallega, revista satírica aparecida en La Habana en 1972. No obstante suele considerarse como pionero de la prensa de la emigración a El avisador galaico (1978), órgano de la Sociedad de beneficencia de los naturales de Galicia en Cienfuegos, dado su carácter de portavoz del pensamiento gallego (Santos Gayoso, 1990; Blanco Campaña, 1995).

También en 1872 en la capital antillana Waldo Álvarez Insua, uno de los periodistas más emblemáticos de la emigración gallega, fundó El eco de Galicia: una publicación ejemplar difusora de la lengua, los valores diferenciales y las inquietudes sociopolíticas de los gallegos (Neira Vilas, 1985; Blanco Campaña, 1995).

Como reflejo del cambio en el destino de la emigración a finales de esta década [años 70] aparecieron las primeras publicaciones en el contexto rioplatense. Las pioneras fueron El Gallego, fundada en 1979 en Buenos Aires por César Cisnero Luces; su némesis, la Revista Galaica, cuya aparición de manos de Eduardo Caamaño suele fijarse en el mismo año (Blanco Campaña, 1995: 115); la Revista del Centro Gallego surgida en 1979 al amparo de dicha institución y, ya en 1880, el semanario La Voz de Galicia dirigido por Benigno Fernández Carvajal en Montevideo.

A partir de estas primeras iniciativas el momento de máxima expansión de la prensa transoceánica se sitúa entre 1900 y 1950, con especial incidencia en la República Argentina donde se editaron más de un centenar de cabeceras de diversa índole ${ }^{7}$ : hay publicaciones del exilio como Galicia Emigrante (1954), semanarios satíricos como O Furón (190), revistas culturales ilustradas como Suevia (1916) o Céltiga (1924), publicaciones bilingües como Almanaque Gallego (1898), de sociedades gallegas como Región Galaica (Centro Gallego, 1907) o Alborada (Orfeón Mindoniense, 1907), publicaciones que Núñez Seixas (2011) denominaría "glocales" como Viveiro en el Plata (1909) o Porriño y su comarca (1925), independentistas como A Fouce (1926) y nacionalistas como A Nosa Terra (1941)

Como señalaba Luís Seoane en el primer número de Galicia Emigrante, considerada una de las mejores publicaciones de la emigración (Blanco Rosas, 2010: 88),

En esta nación donde viven centenares de miles de gallegos, y cuyos descendientes ocupan un porcentaje muy elevado de la población total, queremos contribuir a 
que se distinga nuestra voz diferenciada. Para ello la unimos a las de las publicaciones gallegas que existen actualmente, que vienen realizando una labor notable de la divulgación con auténtica voluntad de sacrificio, y algunas de las cuáles ostentan una indiscutible autoridad (Galicia Emigrante $n^{0} 1$, junio 1954).

Estas cabeceras tuvieron que hacer frente al control y la censura de las autoridades argentinas, que fueron especialmente restrictivas con la prensa del exilio debido a las presiones del gobierno Franquista (González Neira 201:167 y ss.).

Con independencia de las múltiples cabeceras promovidas por la colectividad en "las américas" resulta preciso señalar una importante presencia de periodistas gallegos en la prensa transoceánica, especialmente en rotativos antillanos y rioplatenses. Tal es el caso de Ramón García Vicetto, Manuel Vázquez Castro, Benigno Teijeiro Martínez, Francisco Davila Ugarte, Manuel A. Bares Giráldez, Julio Carballo Enríquez, Miguel Revestido Rodilla, José R. Lence, Amador Víctor González, o Fortunato de Cruces, además de personalidades clave de las letras gallegas como Manuel Curros Enríquez, Eduardo Blanco Amor, Jesús Lorenzo Varela o Xosé Neira Vilas, entre otros.

Dentro del importante volumen de emigrantes gallegos que se alimentaron las páginas de la prensa americana (generalista y especializada) destacan Virginia Felicia Auber y Noya (1825-1897) colaboradora del Diario de la Marina (La Habana) y Mercedes Vieito Bouza (1887-1960) quien durante treinta años participó en diversos rotativos antillanos como Galicia, Heraldo Gallego, Cultura Gallega y el Eco de Galicia, que también dirigió (Neira Vilas, 1985; Simón Palmer, 1991; Costa Alcalde, 1997).

Siguiendo a Eiras Roel y Rey Castelao (1992: 23) el periodismo fue una de las principales actividades de los gallegos con formación, como refleja la importante nómina de profesionales gallegos en la prensa americana amén del importante listado de cabeceras auspiciadas por la colectividad.

Asimismo diversos emigrantes gallegos fueron el germen de cabeceras históricas en los países de acogida como Isidoro Araújo Lima, fundador del Diario de la Marina (La Habana, 1832), uno de los rotativos más influyentes de la capital antillana; o José María Chao Rodríguez promotor de diversas publicaciones, entre ellas la revista $E l$ Ateneo (La Habana, 1868) y el diario político La Legalidad (La Habana, 1874).

\section{Las audiciones históricas de la emigración gallega en América}

El carácter de España como pueblo emigrante y su histórica relación con Hispanoamérica llevó a un rápido desarrollo de iniciativas de radio para el exterior a través de onda corta. La primera de ellas fue la emisora comercial EAQ propiedad de Transradio que comenzó su actividad en 1932 (Montes, 1988). En su programación para 
América esta emisora incluía música, contenidos culturales e información de actualidad, todos ellos de marcado carácter patriótico.

La radio también fue el vehículo elegido por el régimen Franquista para hacer llegar su mensaje propagandístico al exterior. Si bien durante la Guerra Civil ${ }^{9}$ y los primeros años de la Posguerra las "Emisiones para América" vehicularon contenidos puramente propagandísticos, con el inicio de las emisiones internacionales de Radio Nacional de España (en adelante RNE) se creó una programación específica de contenidos musicales de corte folclórico y programas culturales destinados a prestigiar a España apelando a la conexión ancestral con los países americanos (Montes Fernández, 1988; Ortiz Sobrino, 2013).

Cada noche Alicia M. Del Carpio se dirigía desde Madrid a millones de oyentes en Hispanoamérica (Pàmies, 1999: 191). Sólo en la Zona I de emisión -en la que se encontraba Argentina junto a Chile, Uruguay y Paraguay- se consideraba una audiencia potencial de 21 millones de personas (Montes, 1988: 235).

En lo que respecta a la emigración gallega, al igual que había sucedido con la prensa, la colectividad enseguida vio las potencialidades de la radio para la divulgación y propaganda, convirtiéndose en el medio más empleado por las comunidades gallegas en el exterior (González Fernández, 1994).

En el editorial de la revista Galicia Emigrante titulado "Nuestra Audición", el propio Luís Seoane loaba la eficacia del medio sonoro al señalar que "La técnica radial ofrece al público resultados que el libro, la revista o el diario, no pueden abarcar con éxito total" $\left(1954, \mathrm{n}^{\circ} 4\right)$. La radio no sólo exige la atención de un lector también llega a

un grupo familiar, a los varios vecinos de una misma casa; que se introduce a un mismo tiempo en la intimidad de un hogar porteño o de cualquier ciudad o pueblo del interior del país o de las naciones vecinas. Brevísimas crónicas sobre Galicia o sobre su cultura, biografías, noticias, música... emitida con amenidad y simpatía serán escuchadas a un tiempo a las orillas de esta costa atlántica o en las regiones montañosas o llanas del interior. Queremos despertar una conciencia gallega donde quiera que se encuentre, un corazón que se una al nuestro a pesar de la distancia que pueda separarnos (Galicia emigrante, septiembre de 1954).

Esta pretensión quedaría patente con la llegada de Castelao a Buenos Aires (mayo 1940). Entre los actos de bienvenida del "máximo representante de Galicia en América" (Vilanova: 1957) se incluyó un recorrido por las emisoras de la capital porteña (Blanco Rosas, 2015: 211).

Como señala Vilanova $(1957,1420$ y ss.) la radio se erigió como el complemento propagandístico perfecto de la tribuna y la prensa, especialmente en Argentina pionera mundial en el desarrollo de la radiofonía (Agusti y Mastrini, 2006).

La concentración de la industria radiofónica en Buenos Aires, principal asentamiento de la colectividad gallega, favoreció su acceso al medio y una mayor atención en los contenidos de las emisoras (Piñeiro-Otero y Cofrades, 2016). 
Blanco Rosas $(1998,2015)$ recopila más de una treintena de audiciones radiales - de diverso recorrido y trascendencia- dirigidas a la colectividad gallega en Buenos Aires, un fenómeno que se reiteró en menor medida en otros países Latinoamericanos (Blanco Campaña: 1995 y 1999; Rebolo Vázquez, 2008 y 2010) .

Muchas de estas emisiones surgieron al amparo de centros y sociedades gallegas, integrando contenidos de interés para sus promotores así como su agenda de eventos. Entre estas audiciones suele destacarse la del Centro Lucense de Buenos Aires (19561967) a cargo de Luís Seoane y parte del equipo de Galicia Emigrante (Palmás, 1978). Sin embargo los programas con mayor proyección en la colectividad gallega resultaron de iniciativas privadas, del trabajo y compromiso de personas cuyas voces quedaron registradas en la memoria colectiva de la Galicia austral.

En Buenos Aires también debutó el pontevedrés Manuel Núñez Búa, "el más antiguo locutor de radio de nuestro país" siguiendo a Blanco Campaña (1995:26).

Antes de que en Galicia existiese radio, Núñez Búa ya triunfaba en Radio Buenos Aires LR7 con La Hora Ibero-Americana (1932-1937). Esta audición de temática española dedicaba un espacio destacado a la cultura gallega en el que contaba con la colaboración de diversos artistas de la colectividad como el insigne actor Fernando Iglesias (en adelante Tacholas) para quien Núñez Búa fue "su padrino radiofónico" (Pérez Rodríguez, 1996:240).

En este programa Tacholas contaba cuentos, teatralizaba textos y hacía comentarios sobre cuestiones gallegas (Mejía, 2011: 244) aportando una perspectiva diferente y dignificadora del ser gallego respecto a las bufas popularizadas en las emisoras porteñas por Niní Marshall (Seoane en Braxe y Seoane, 1989: 184 y ss.).

El éxito recabado por el programa de Núñez Búa propició la aparición de formatos similares en otras emisoras rioplatenses. De entre ellos solamente La Audición Hispano-Argentina (1936 -1938) dirigida y conducida por el compositor gallego José Barreiro, en colaboración con Maruja Villanueva, incluía contenidos específicamente gallegos convirtiéndose en su principal competidora tanto en términos de audiencias como de financiación (Pérez Rodríguez, 1996),

La entidad de la colectividad gallega en la capital y la penetración de la radio en ésta llevaron a las emisoras a incorporar audiciones radiales especializadas. La pionera fue La Hora gallega (1933-1935) de José Rodríguez de Vicente en Radio Patria. Si bien Samuelle (2000: 233) señala una iniciativa previa en Uruguay, Airiños da miña Terra, Blanco Rosas (1998: 194) data el inicio de este programa en 1935.

La Hora Gallega supuso el punto de partida también esbozó algunas de la características de la radiofonía histórica de la emigración, como el posicionamiento político-cultural, el protagonismos del exilio, o la crítica al tratamiento mediático de los gallegos (Blanco Rosas, 2015: 193).

Más allá de estas primeras iniciativas la radiodifusión gallega en el exterior vivió una notable expansión y madurez a partir de la década de los 40 . 
El primer programa de esta etapa dorada de la radio de la emigración gallega fue Galicia, Arte y Cultura para la colectividad gallega (1939-1945, en adelante Galicia) dirigido por Maruja Villanueva en LR2 Radio Argentina. Esta audición, con un formato próximo al magacín, incluía entre sus contenidos música popular y tradicional (grabada y en directo) así como recitales de textos de Rosalía de Castro, Manuel Curros Enríquez y de otras primeras plumas de la literatura gallega (Pérez Rodríguez, 1996: 47). Desde los micrófonos de este programa se pudieron escuchar a algunos de los integrantes de la Compañía de Comedias de Maruja Villanueva como Tacholas o Maruja Boga, piezas clave en la historia de la radio de la emigración. .

En 1945 Maruja Boga, junto a Tacholas, Enrique González y Alfredo Arostegui pusieron en marcha Recordando a Galicia (1945-1984). Esta audición, auspiciada por Castelao, comenzó a emitirse en Radio Prieto aunque fue en Radio Rivadavia donde se consolidó como uno de los programas más representativos de la emigración gallega.

Años más tarde, en 1953, Tacholas salió al aire con La Voz de Galicia (1953-1954), una emisión "de tono costumbrista y esencialmente folklórico, llevando él sin auxilio de nadie su plausible labor" (Vilanova, 1957:1423).

Si bien estas tres audiciones vehiculaban contenidos folclórico-sentimentales, puede observarse el uso de la cultura como una forma de concienciación identitaria y política, construyéndose como un medio para fomentar el orgullo de pertenencia y la transmisión de una serie de valores ideológicos inherentes a la condición de gallego (Blanco Rosas, 2015: 413). Estas emisiones también constituyeron un poderoso altavoz de la agenda de actividades de las diversas entidades de la colectividad, función que ha constituido una constante en las audiciones radiales de la emigración gallega hasta la actualidad.

El posicionamiento ideológico y político de estos primeros espacios se hizo especialmente patente en las audiciones radiales del exilio: el célebre Galicia emigrante (1954-1971) de Luís Seoane, quien desde Radio Libertad llevó la voz de la revista al seno de los hogares argentinos con entrevistas a diversos actores de la colectividad así como reseñas de "los más diversos aspectos de la vida gallega de los siglos pasados y las últimas décadas" (Palmás, 1978: 29); y Galicia en el Aire (1958-final década 60) de Andrés Rodríguez Barbeito espacio que constituyó un "pregón de rebeldía" y en el que se defendían los valores históricos de Galicia frente al Franquismo (Vilanova, 1957; Neira Vilas, 2001).

\section{Como señalaría el propio Seoane en su editorial sobre Recordando a Galicia}

Es difícil comprender, por los ajenos al periodismo radial el trabajo que significa sostener con éxito la atención durante años de los radio oyentes y el desinterés que significa consagrar ese esfuerzo a una causa patriótica en la que redactores y locutores deben dirigirse por igual al sentimiento y a la inteligencia del auditor no tratando de llenarlo de este género de estupefacientes que se propagan por las emisiones radiales (en Braxe y Seoane, 1989:168) 
A comienzos de esta misma década, en Montevideo, Manuel Meilán se sentaba frente a los micrófonos de Radio Carve para iniciar la primera emisión de Sempre en Galicia (1950-actualidad). Los promotores de esta audición pretendían dar continuidad a la labor de Castelao y expandir la lengua y cultura de Galicia. "Seguramente ni soñaban siquiera con que la audición dejara una huella tan profunda en la colectividad" uruguaya pero también de buena parte de Argentina y el sur de Brasil dada la potencia de emisión de Radio Carve (Rebolo, 2011: 49; 2002).

Si La hora de Galicia, de José Rodríguez de Vicente fue pionero de la radiofonía de la colectividad gallega en la otra orilla del río de La Plata, Sempre en Galicia de Manuel Meilán constituyó el primer programa radiado completamente en gallego y -en la actualidad- el decano de la radio de la emigración.

Allén del contexto rioplatense se pueden señalar iniciativas de audiciones radiales de la emigración en otros países latinoamericanos como el Sempre en Galiza (1955, Caracas) de la Irmandade Galega de Venezuela, o el mexicano Hora de Galicia (1951, Méjico DF) del galeguista exiliado Eligio Rodríguez que se radió durante años en XEMC emisora regentada por el ourensano Ramón Ferreiro y que sucumbió a manos de la censura (Rodríguez, 1994).

En el caso de Cuba, cuna de la prensa emigrante, el particular contexto político hace complejo abordar el fenómeno de la radio de la emigración gallega (Blanco Campaña, 1999: 24), si bien existe constancia de intervenciones de Castelao en la radio antillana así como de una iniciativa del intelectual galeguista Xerardo Álvarez al final de los años 30 .

Al igual que sucedía con la prensa se puede destacar la presencia de gallegos en audiciones radiales no específicamente relacionadas con Galicia como los literatos Xavier Bóveda (1898-1963) quien entre 1934 y 1935 desarrolló Tertulias literarias en Radio Prieto (Buenos Aires) popularizando la muletilla de "En España, la jurisprudencia" (Lorenzo Alcalá, 2009:14); o Lorenzo Varela (1917-1978) al frente del programa cultural Asimismo por los micrófonos de las emisoras de los países de acogida de la Galicia emigrada, al igual que por las audiciones de la colectividad, pasaron personalidades de la emigración y el exilio e incluso se radiaron colaboraciones de intelectuales del otro lado del Atlántico. Muchos de los programas fueron promovidos o apadrinados por figuras emblemáticas quienes "en calidad de intelectuales certificaban con su presencia el compromiso galeguista de la iniciativa" (Blanco Rosas, 2015: 214).

En general los programas radiales históricos de la colectividad ayudaron a divulgar cuestiones y temas "da Terra" para el gran público, inculcando el sentimiento identitario entre emigrantes a los que no se hubiese llegado de otra manera (Farías, 2007: 369).

Estos espacios compartían dial con los programas de otras colectividades y con la emisión internacional de RNE que, tras la apertura del centro transmisor en onda 
corta de Arganda del Rey (1945), se convirtió en una alternativa de calidad (técnica $\mathrm{y}$ de contenidos).

De las primeras retransmisiones exteriores de RNE, centradas en conferencias de eruditos americanistas, se pasó a una planificación estratégica de contenidos de entretenimiento destinados a atraer a radioescuchas de Hispanoamérica así como a españoles emigrados. A partir de estas dos tipologías de públicos se conformó una programación para América que incluía, además del Diario hablado de España para América, música española -folclórica, ligera o composiciones clásicas-, radioteatro español, programas literarios y artísticos de la vida americana (elaborado por diplomáticos de los respectivos países en Madrid) o radio revistas de temática española (Montes, 1988).

Como escribió Eugenio Suárez (1946) en el diario Ya

La emisora de Arganda, ha venido a llenar este inmenso vacío, este anacronismo que nos retardaba explicablemente en crédito universal. Y ahí están esos emocionantes controles que llegan de América con plebiscito de amor y reconocimiento a la lejana patria del gallego, que siente ahora la mitigada nostalgia de veinte años de emigración (citado en Montes, 1988: 240).

Al igual que los magacines de la colectividad gallega la emisión para América de RNE se basaba en una selección de manifestaciones culturales, de fuerte carácter patriótico, para incrementar el prestigio de España en el exterior así como para fomentar el sentimiento identitario y el orgullo de pertenencia entre los emigrados.

Al margen de estas emisiones española en onda corta, a medio camino entre la propaganda franquista y la radio servicio (Pàmies, 1988: 186), uno de los mejores ejemplos de las audiciones que vehicularon contenidos de corte étnico para la concienciación social y política fue siguiendo a Blanco Rosas (2004: 211 y ss.) Recordando a Galicia. Un programa radiofónico cuya alma y voz, Maruja Boga, ha constituido el objeto de estudio del presente artículo.

\section{Materiales y métodos}

En agosto de 2015 se planteó un estudio sobre el papel de las audiciones radiales contemporáneas en la difusión de la identidad gallega. Como parte de este estudio se llevó a cabo un total de doce entrevistas en profundidad a personalidades de la colectividad gallega en Buenos Aires, así como a responsables de las cuatro iniciativas radiales de temática gallega (más una española patrocinada por el Centro Galicia) que continúan en activo en la capital porteña ${ }^{10}$. Como complemento a dichas entrevistas se desarrolló un grupo de discusión con integrantes do Terzo da Fala, colectivo cultural galaico-porteño.

En el transcurso de estas entrevistas se puso de manifiesto la persistencia del recuerdo de algunas de las audiciones históricas, que semana a semana conquistaban 
sus hogares, y de aquellas voces que los conectaron a Galicia incluso cuando no la conocían (en torno a un tercio de las respuestas eran de gallegos de segunda generación).

No obstante a la hora de reseñar estas voces prácticamente todos los participantes coincidieron en señalar a Maruja Boga, a veces junto a Alfredo Arostegui, y a su audición Recordando Galicia.

Una cuestión que resultó destacable en tanto que la audición de la emigración más reconocida desde la perspectiva de la Galicia territorial es Galicia Emigrante de Luís Seoane; un programa que apenas fue mencionado en las entrevistas.

En un primer momento se consideró que el mayor recuerdo de Boga frente a Seoane, podría estar motivado por la proximidad y tiempo de emisión de los programas. Recordando a Galicia estuvo en antena casi cuatro décadas, hasta 1884, llegando a diversas generaciones de gallegos australes.

Sin embargo la reseña de otros nombres históricos de la radiofonía gallega como Tacholas o Núñez Búa remite a un mayor calado de los programas de entretenimiento en la memoria colectiva de la emigración.

El nombre de Maruja Boga también estuvo presente en conversaciones informales con integrantes de algunas de las entidades y asociaciones gallegas de la capital porteña. Alguno de los cuáles recordaba cómo cada sábado se imponía el silencio en casa para que sus abuelos pudiesen, a través del dial de su receptor de radio, asomarse a Galicia.

En las entrevistas a comunicadores radiofónicos se reiteró esta idea, situando a Boga como un referente de la radiofonía gallega actual en el país rioplatense.

No obstante, pese a su relevancia en el seno de la colectividad gallega en Argentina apenas se han encontrado referencias sobre esta actriz y locutora gallega.

Frente a los diversos trabajos publicados sobre la audición Galicia Emigrante y la faceta periodística de Luis Seoane (véanse por ejemplo Blanco Rosas, 2010; Braxe y Seoane, 1989; o González Fernández ); Sempre en Galicia de Manuel Meilán (Rebolo, 2002 y 2011) o incluso sobre Fernando Iglesias “ Tacholas” (Pérez Rodríguez, 1996), el papel de Maruja Boga en Recordando a Galicia aparece fragmentado en estudios sobre la radio gallega en la emigración (Blanco Campaña, 1995 y 1999; Cabo, 1999; Rebolo, 2011 y 2007; Blanco Rosas, 1998 y 2015), y en algunas de las informaciones publicadas con motivo de reconocimientos y homenajes o de su fallecimiento (2010).

En este sentido, el presente trabajo pretende efectuar una semblanza de esta voz tan representativa para la colectividad gallega en Buenos Aires, cuando se cumplen cien años de su nacimiento. Para ello se han empleado cuatro métodos diferentes de recogida de la información: las mencionadas entrevistas semiestructuradas y grupo de discusión; el análisis bibliográfico y el estudio de fuentes secundarias.

Un abordaje metodológico que pretende profundizar en la faceta de comunicadora de Maruja Boga cuando ya no se conservan grabaciones históricas de Recordando 
a Galicia, aunque sí algunas transcripciones de sus editoriales en la prensa de la emigración.

\section{Maruja Boga, una personalidad polifacética y comprometida}

Por distintas emisoras de esta capital un núcleo de hombres patriotas vienen desarrollando una magnífica labor, en audiciones distintas desde hace años; nosotros queremos contribuir con la propia a la mejor exaltación de Galicia, deseando tener nuestro sello característico, pero unidos en la emoción a ellos, a quienes saludamos con respeto, fraternalmente.

Estas palabras recogidas en la revista Galicia emigrante (septiembre de 1954), con motivo de la puesta en antena del programa, suponen un reconocimiento a las audiciones y comunicadores precedentes, al tiempo que un intento de Luís Seoane de integrar su espacio en una tradición de radio emigrante gallega.

En esta tradición se pueden señalar diversas mujeres con nombre propio como María del Pilar Lebrón quien puso su voz a los textos de Seoane en Galicia emigrante, Maruja Villanueva conductora y productora de espacios históricos de la radiodifusión galaico-porteña, Elsa Fernández promotora -junto a Xosé Neira Vilas- de Mirador Bibliográfico Galego (1958-1963) y, por supuesto, Maruja Boga.

María Josefina Boga Romaní, más conocida como Maruja Boga, nació el 27 de marzo de 1916 en el barrio bonaerense de Barracas. Hija de padres gallegos que

(...) supieron inculcarle el amor a la Tierra de sus mayores y desde niña se ha entregado con pasión al servicio de las más nobles causas de Galicia, para lo que no ha regateado esfuerzos y sacrificios, y estuvo y está siempre dispuesta a todo lo que conduzca a la exaltación y prestigio de la Madre Patria Gallega (Vilanova, 1957: 1422).

Esta intensa labor a favor de Galicia y de la colectividad emigrante llevó a Luís Seoane a calificarla como una "auténtica patriota", gallega por "ius sanguini" y argentina por "ius solis" (Porteiro y Torres, 2012).

En una de las editoriales de Recordando a Galicia Boga se reafirma como gallega para criticar a aquellos emigrantes que renegaban de su origen para abrazar el canon porteño.

Quien estas palabras les dice, argentina de nacimiento, y que siente el legítimo orgullo de ser por privilegio y gracia de la Providencia, es también gallega por afinidad, porque esa es la patria de sus padres y porque a esa patria debe el caudal de su cultura y de sus aspiraciones espirituales. Y es por ello también que ve con dolor como los gallegos nativos, lejos de sentirse orgullosamente tales, entregan el preciado don de su origen al bastardo sentimiento entreguista que lo niega todo sin construir nada. En esta época de confusiones mayores, es menester saber quién es quién y por qué se es algo... cuando se es (En Rodríguez, 2011: 46). 
Precisamente esta consciencia de su identidad y de su origen fue el germen de su profundo compromiso con Galicia que le llevaría a la radio, como confesó en una entrevista radial en Galicia Emigrante:

Mis padres fueron emigrantes que llegaron a Argentina a luchar por un lugar entre los muchos y generosos que se le ofrecían. Aquí quedaron y fundaron un hogar permanente. Nunca regresaron a la tierra natal mas me educaron en un ambiente de amor a su patria, que yo aprendí a querer y respetar. Para ellos la vida no fue fácil. Pero lo que no pudieron realizar en su juventud, lo vieron florecer en mí. Tenía una deuda con ellos y debía cumplirla. Por eso, al regresar a la Academia Nacional donde cursé mis estudios me propuse dedicar la vida a la exaltación de la "cosa" gallega. Así llegué a la radiofonía y de allí al teatro (en Braxe y Seoane, 1996: 231).

Con tesón y, como ella misma diría "un coraje bárbaro", Boga fue dando pequeños pasos por la dignificación del gallego y lo gallego.

En 1935 recién titulada en el Conservatorio Nacional de Música y Declamación fue con Maruja Villanueva a una audición en Radio Prieto donde tuvo sus primeros contactos con las ondas (Suárez 2012: 2). Partiendo del tipo de programas que triunfaban en la radio porteña es probable que este primer contacto fuese interpretando una canción, un poema o un texto dramático.

Poco después, con el carnet de locutora nacional número 1010, Boga pasaría a ejercer como locutora oficial de Radio Rivadavia (Blanco Rosas, 2015: 217).

En 1939 se integró en Galicia de Maruja Villanueva, con quien compartió la conducción del programa que tenía a Tacholas entre sus principales colaboradores.

Fuera de los estudios Maruja Boga también mantuvo una fructífera relación profesional con ambos artistas. Como parte de la Compañía de Comedias de Maruja Villanueva participaron en la puesta en escena de diversas obras de Varela Buxán en teatros de Buenos Aires, Rosario y Montevideo (Suárez: 2012: 2).

El 14 de agosto de 1941 esta compañía estrenó en el Teatro Mayo la obra de Castelao Os vellos non deben namorarse, donde Boga detentaba el protagonismo del último acto. Posiblemente fue en este montaje donde se fraguó la relación entre Maruja Boga y el insigne galeguista, promotor y padrino de Recordando a Galicia.

En esta etapa de la radiodifusión argentina existía una estrecha relación entre el teatro y la radio. Los programas de mayor éxito en las parrillas de las emisoras eran tipo magacín, en los que solía incluirse sketches, y los radioteatros; dos formatos que se nutrieron de los elencos teatrales. La propia Eva Duarte de Perón "Evita", fue una de las numerosas voces que dieron vida a dichas ficciones sonoras en la década de $\operatorname{los} 30$.

Este vínculo fue mayor en el caso de las compañías teatrales gallegas debido a su proximidad a los círculos galeguistas. 
La implicación de Maruja Boga con el teatro gallego, como una forma de activismo político, la llevó a fundar su propia compañía junto a Tacholas en la década de los 60: La Compañía de arte folclórica Boga-Tacholas.

Cuando íbamos a los festivales (...) con Tacholas, y hacíamos sketches y hablábamos en gallego. Y como todos era argentinos de pañuelito y chamberguito y bailando tango, no entendían un corno [cuerno] de gallego. Entonces les decíamos una cosa en gallego y enseguida les explicábamos en castellano, y así íbamos enseñándoles cómo era el gallego.

Dicha compañía continuó la lucha por un teatro gallego estable que Maruja Villanueva había abanderado y de la que también formaron parte Varela Buxán, Seoane o Díaz Pardo (Corral, s/d).

El compromiso de Boga con el ideario galeguista "le llevó a luchar con igual entusiasmo por la causa republicana española, sin reparar en toda clase de dificultades" (Vilanova, 1957:1422). Este posicionamiento le llevó a denunciar desde su espacio radial tanto los problemas que aquejaban a la emigración o a la colectividad en Argentina como a defender al exilio (Soto, 2003).

Además de constituir un referente como actriz y radialista Maruja Boga fue profesora en la Academia Nacional de Arte Escénico y Declamación (Vilanova, 1957: 1422) participando en la formación de generaciones de locutores (Rosas, 2015: 219).

Su faceta docente no termino ahí sino que, según recogen Porteiro y Torres (2002), ejerció como profesora de lengua y literatura gallegas en la colectividad porteña, en un ejemplo más de su compromiso con el galeguismo y la emigración. Sin embargo el uso de esta lengua, que Maruja dominaba (Vilanova, 1957: 1422), estuvo bastante limitado en las ondas y sometido a la censura (entrevista personal de Ramón Suárez, Muxo).

En Radio Prieto, conoce a Alfredo Arostegui quien será su compañero de vida y profesión. El "locutor olímpico" había ejercido como corresponsal de guerra Galicia durante la Guerra Civil de donde volvió con "sangre en el ojo" y "tan desesperado, que cuando nos conocimos, en octubre del año 39, resolvimos hacer algo por Galicia” (Boga, 2008: 2). Este algo fue una audición, Variedades (1939-1945), en la que siempre introducían algún contenido gallego con el que burlaban la prohibición del dueño de la emisora, Teodoro Prieto, sobre este tipo de programas.

En 1945 Radio Prieto les exigió alquilar el espacio en antena, un cambio que si bien dejaba su subsistencia en manos de la consecución de financiación, dotó a Boga y a Arostegui de la independencia suficiente para definir sus contenidos. Con Enrique Gonzáles y Tacholas se lanzaron a la búsqueda de anunciantes y patrocinadores y así, "el 5 de agosto del 45 nació Recordando a Galicia, que nació de la mano de Castelao, nuestro guía, nuestro norte" (Boga, 2008: 3).

En uno de los textos compilados por Pérez Rodríguez (1996: 250) Tacholas subraya el relevante papel de Castelao en la histórica audición "por su sugerencia fundamos en Radio Prieto, Recordando a Galicia, siendo él en tal ocasión, el padrino 
fundador de la audición". Este apadrinamiento fue muy significativo. El hecho de que el insigne galeguista apoyase a Recordando a Galicia entre las numerosas iniciativas radiales de la capital porteña y, en general, te toda América legitimó al programa como el referente radial de la colectividad.

\section{Algo más que una voz. Boga en Recordando a Galicia}

El contenido de las entrevistas y el grupo de discusión constató que Recordando a Galicia constituye la audición cuyo recuerdo ha permanecido más vívido en la memoria colectiva de la emigración gallega, al igual que la voz de su directora y conductora.

Como recordaba Ramón Suárez Muxo en entrevista personal con las autoras (Agosto 2015).

(...) Yo la conocí [a Maruja Boga] ya grande pero los sábados a la tarde, cuanto ella tenía su programa, pasabas por las aceras y se escuchaba que salía a través de las ventanas, de las puertas, de los rincones a Marujita. Todo el mundo le decía Marujita, todos sus oyentes, ya tenía 70 años y le decían Marujita. Pero ella fue lo más grande que hubo (...).

Un ejemplo de la penetración de este programa entre la colectividad galaico-porteña fue el aviso del boletín societario del Centro Betanzos en el que se indica el fin de las comunicaciones ordinarias por correo a favor del programa Recordando a Galicia, que informará de todas las cuestiones de relevancia y agenda social de la entidad. En este mismo aviso se invita a los socios a escuchar "Crónicas Betanceiras" un microespacio dedicado a Betanzos en el marco de la célebre audición (Betanzos, agosto 1964: 63).

Con motivo del cierre de Radio Ribadavia en 1961, Luís Seoane radia un editorial beligerante en defensa de la audición Recordando a Galicia de cuya trayectoria efectúa una breve reseña:

Sus directores primeros, sus fundadores, fueron la actriz Maruja Boga y el locutor Arostegui, el actor gallego Tacholas y el dinámico y eficaz dirigente del Centro Ourensán, Enrique González. Años más tarde quedarían únicamente en su dirección Maruja Boga y Arostegui Tacholas abandonó el primero el equipo de "Recordando a Galicia", apremiado por solicitudes profesionales, y Enrique González más tarde, porque pasó a desarrollar sus actividades comerciales en el sur argentino. Maruja Boga, Tacholas y Enrique González consolidaron su prestigio en la colectividad gallega como actores de "Os vellos non deben namorarse", dirigidos por el propio Castelao, representando cada uno de ellos papeles que, pasando el tiempo, resultan inolvidables. En los tres y en Arostegui se unió, en Recordando a Galicia, las condiciones artísticas e intelectuales, su fondo fervor gallego, aún habiendo nacido en esta república, excluyendo el caso del orensano Tacholas (en Braxe e Seoane 1996: 167). 
Recordando a Galicia presentaba una fórmula similar en contenidos y secciones a Galicia de Maruja Villanueva, además de compartir elementos estilísticos, estructurales e incluso ideológicos (Blanco Rosas, 2015: 228).

Maruja Boga detentaba el peso de la conducción del programa, además de encargarse de "recitales poéticos y sabrosísimos monólogos en idioma gallego que domina plenamente, así como de los graciosos diálogos sostenidos con Enrique Alfredo González, hijo de orensanos y fielmente compenetrado con el ideario galleguista, abriendo casi siempre la audición con un valiente editorial (...)" (Vilanova, 1957: 1422).

El posicionamiento político de Recordando a Galicia se dejaba ver tanto en la antología histórica "De la Galicia de todos los tiempos" como en la selección de invitados literarios, que leían en antena un fragmento de su obra y -ya de carácter más puntual- las entrevistas.

En palabras de Seoane "Cada audición constituyó un llamamiento a las conciencias gallegas. La alerta necesaria para que nadie llegase a engaño sobre el presente de Galicia" (Braxe e Seoane 1996: 167). Un llamamiento que se hizo especialmente patente en "Nuestra editorial de hoy" espacio en el que Maruja Boga abordaba diversos temas relacionados con Galicia o con la emigración.

El surgimiento y expansión de radiofonía gallega en Buenos Aires se sitúa en una etapa política convulsa en el país rioplatense. Durante la Década Infame (1930-1943), en la que se sucedieron diversos golpes de estados y gobiernos inconstitucionales, y las posteriores etapas políticas las emisoras implantaron un sistema de control de contenidos instadas por el poder político. Un poder coercitivo que clausuró Radio Ribadavia en 1961. "No entramos a analizar las razones que hicieron suspender la esta emisora, aunque también sea cuestión nuestra en la que todos deberíamos tener opinión sino en cuanto nos afecta por dejarnos sin un órgano profundamente gallego que nosotros respetamos por su historia y por su deseo de verdad" (Seoane en Braxe y Seoane, 1989: 168).

En diversas ocasiones Maruja Boga retó este control incluyendo en sus editoriales denuncias veladas sobre como la política franquista estaba afectando a Galicia, los problemas de la emigración en los países de acogida o cualquier tipo de injusticia, siempre manteniendo una postura de defensa de Galicia, de la cultura gallega y sus gentes (Blanco Rosas, 2015: 214). En sus editoriales a Boga tampoco le tembló la voz a la hora de denunciar algunos vicios o desmanes en el seno de la colectividad (Vilanova, 1957:1422).

Este compromiso llevó a su contemporáneo Luís Seoane a describir la labor de Maruja Boga como "verdadero periodismo libre, pobre, honesto e independiente". En su editorial sobre Recordando a Galicia Seoane efectúa un alegato sobre el periodismo independiente y sus dificultades, refiriéndose a Boga y Arostegui pero también a él mismo 
Ellos (...) y tantos periodistas de audiciones similares a estas, o de semanarios de pequeña tirada, nos hemos habituado a seleccionar la noticia oculta o trucada de las grandes agencias noticiosas y de los grandes periódicos para hacer nuestro comentario referido a Galicia y nos integramos con los numerosos David del mundo que se enfrenta a los Goliat del terror y la mentira (en Braxe y Seoane, 1989:168)

En su dilatada trayectoria Recordando a Galicia estuvo sujeto a cambios de emisoras, cierres temporales e incluso, si atendemos a la tesis de Blanco Rosas (2015:229) a períodos de inactividad.

Al año de iniciar su andanza en Radio Prieto, el programa pasa a emitirse en Radio Ribadavia donde permanecerá en antena 16 años, hasta la clausura de la estación por las autoridades.

Tras este cese forzado, Boga y Arostegui, buscaron otro espacio para la célebre audición. Blanco Rosas (2015: 229) habla de un impás de siete años, una afirmación que contrasta con las numerosas alusiones -en fuentes bibliográficas y entrevistasa las cuatro décadas de emisión ininterrumpida. Sea como fuere se puede señalar una tercera etapa del programa en la que Recordando a Galicia vuelve a resurgir, e incluso a duplicar su presencia en el dial con sendas audiciones en LS Radio América y la Radio Antártida (Blanco Rosas, 2015: 229).

El 25 de marzo de 1984 apagó definitivamente sus micrófonos, un final anunciado por la paulatina pérdida de financiación. A lo largo de los años fueron continuos los llamamientos, incluso desde la prensa de la emigración, a la colaboración de entidades y anunciantes para que Recordando a Galicia pudiese seguir adelante en su labor de "exaltar a un pueblo laborioso y honesto" como recordaba la cabecera del programa.

La pérdida de apoyos hizo que Maruja Boga se separase de la colectividad en sus últimos años de vida, especialmente tras la muerte de Arostegui en 1985. Como señaló uno de los entrevistados, "Maruja nunca perdonó a entidades y avisadores la falta de respaldo" a una audición cuya máxima aspiración era que "Galicia, la eterna Galicia, sea más conocida, más comprendida y por ende más respetada" (La Opinón Gallega, septiembre de 1946).

Este distanciamiento refleja el carácter de esta personalidad polifacética e implicada la voz de la emigración gallega en Buenos Aires. Boga fue coherente con su ideal galeguista y su compromiso con Galicia, que dejó patente hasta el final de su vida (26 de julio de 2016).

En el año 2008 en el homenaje que le brindó la Xunta de Galicia, en aquel momento presidida por el socialista Emilio Pérez Touriño, finalizó su intervención diciendo "me acunaron en gallego y así salí hablando gallego. Quise a Galicia terriblemente, la quiero... y espero no poder morirme sin verla totalmente recuperada, porque todavía creo que le falta" (Boga, 2008). Una declaración que dejó patente cuál era el destino que ella, como Castelao, había soñado para su Galicia Ideal. 


\section{A modo de conclusión}

Maruja Boga fue una personalidad polifacética, comprometida con el galeguismo y la emigración. Esta implicación le llevó a crear su propia audición radial para defender -como ella misma diría- "la cosa gallega".

Su determinación a la hora de atacar o defender determinadas situaciones o actitudes que afectan a Galicia, a la emigración o el exilio, y su denuncia de la injusticia refleja un papel que trasciende al de actriz, locutora e incluso conductora del programa.

Sin embargo en todas las biografías o referencias sobre Boga encontradas se reitera sin cesar su papel de actriz y se limita su experiencia radial al rol de locutora de la célebre audición Recordando a Galicia. Dos facetas que Blanco Rosas (2015: 2018) combina para legitimar el papel de Maruja Boga como periodista divulgativa de la galleguidad y de la cultura.

Es su contemporáneo Luís Seoane quien defiende, de forma más o menos directa, el carácter de Boga como periodista en un célebre editorial que constituye un alegato sobre el periodismo radiofónico independiente.

En Recordando a Galicia Boga desarrolla la insigne labor del verdadero periodismo, de resistencia ante los embates de los poderes públicos e incluso de dentro de la propia colectividad. No obstante conoce a su público, porque forma parte de él, del "pueblo laborioso y honesto" de la Galicia emigrada que sueña con la otra Galicia que dejaron atrás. Estos cientos de mujeres y hombres que sintonizan Recordando a Galicia cada semana, su particular vínculo con "a Terra".

Para estos gallegos que -como señaló un entrevistado- desconocían la riqueza cultural de su pueblo y llegaban a Argentina avergonzados, el activismo cultural de Maruja Boga les permitió el desarrollo de su identidad, suscitó el orgullo de pertenencia y -con este- de ciertos postulados galeguistas. Y lo hizo con la música, los poemas, los fragmentos dramatizados de teatro, los cuentos, la historia de Galicia... dejando una profunda huella en la colectividad que sigue vívida, más de treinta años después del fin de sus emisiones.

La singularidad de esta iniciativa y de su trascendencia ha llevado a Blanco Rosas $(2015,253)$ a preguntarse por la fórmula del éxito de Recordando a Galicia respecto a las numerosas audiciones de la colectividad del que ocuparon el éter. La respuesta es, sin lugar a duda, Maruja Boga. Como se señalaba en El Orensano (25 de mayo de 1946), Boga desarrolló una nueva modalidad de audición que benefició a la difusión de la identidad gallega a través de los valores artísticos, literarios e históricos.

Las iniciativas que siguen hoy en el aire, así como las generaciones de gallegos que escucharon a Boga a través de los micrófonos de Radio Prieto, Radio Ribadavia o -más recientemente- de Radio América o Radio Antártida deben mucho a esta actriz, locutora, conductora, directora y -por supuesto- periodista; parafraseando a Rebolo (2002) quizás la más sentida de la radiodifusión gallega. 


\section{Referencias bibliográficas}

AGUSTI, M. y MASTRINI, G. (2006). "Radio, economía y política entre 1920 y 1945. De los pioneros a las cadenas". En: MASTRINI, G. (Coord.). Mucho ruido, pocas leyes: economía y políticas de comunicación en la Argentina 19202004. Buenos Aires: La Crujía.

Betanzos. Órgano oficial del Centro Betanzos, n 59, agosto 1964 (Buenos Aires).

BLANCO CAMPAÑA, X.L. (1995). Radio e prensa na Galicia Exterior. Santiago de Compostela: Xunta de Galicia.

(1999). Historia da radio en Galicia. Santiago de Compostela: Edicións Lea.

BLANCO ROSAS, J.J. (1998). "Os programas radiais dos emigrantes galegos". En: Estudios migratorios, $n^{\circ} 6$, Santiago de Complostela: Consello da Cultura Galega. P. 189-207.

(2015). Historia da radiodifusión galega en Arxentina : (1930-1984). Tesis de doctorado presentada en el Departamento de Historia Contemporánea y de América, Facultad de Geografía e Historia. Universidad de Santiago de Compostela.

BOGA, M. (2008). "Discurso en el acto de homenaje en el que se da su nombre al Salón de Actos de la Delegación de la Xunta de Galicia en Buenos Aires". En: Álbum de mulleres, Consello da Cultura Galega [En línea]. Recuperado el 30 de marzo de 2016 de http://goo.gl/TIZCro

(2008b). "Palabras finales de la intervención de Maruxa Boga" [Vídeo]. ". En: Álbum de mulleres, Consello da Cultura Galega [En línea]. Recuperado el 30 de marzo de 2016 de https://goo.gl/6yevmp

BRAXE, L. y SEOANE, X. (1989). Escolma de textos de la audición radial de Luis Seoane "Galicia Emigrante" (1954-1971). Sada: Edicións O Castro. (1996). Luís Seoane e o teatro. Sada: Edicións O Castro.

CABO, X.L.: "O Rego da cultura. A radiodifusión galega no exterior", Revista Grial, $n^{\circ} 142$ (1999), Editorial Galaxia: Vigo. p. 357-360.

CASTIÑEIRA CASTRO, V.M. y MARTÍN GARCÍA, A. (1999). Dun Finisterre a outro: a emigración galega á Patagonia. Santiago de Compostela: Xunta de Galicia.

COSTA ALCADE, M. X. (1997). Mulleres galegas na prensa galega de América (1873-1914): O caso de Mercedes Vieito Bouza. En: Estudios Migratorios, $\mathrm{n}^{\circ} 3$. Santiago de Compostela: Consello da Cultura Galega, p 257-284.

El Orensano, 25 de mayo de 1946 (Buenos Aires).

EIRAS ROEL, A. (1991). "La emigración gallega a América: panorama general". En: EIRAS ROEL, A. (Coord.) (1991). La emigración española a Ultramar, 14921914. Madrid : Ediciones Tabapress. P. 17-40.

(1992). "La emigración gallega a las Américas en los siglos XIX y XX. Nueva panorámica revisada". En: EIRAS ROEL, A. (Ed.) (1992). Aportaciones al estudio de la emigración gallega. Un enfoque comarcal. Santiago de Compostela: Xunta de Galicia. P. 185-189.

EIRAS ROEL, A. y REY CASTELAO, O. (1992). Los gallegos y América. Madrid: Fundación MAPFRE. 
FARÍAS, R. (2007). "La ciudad gallega más grande del mundo". En: FARÍAS, R. (Comp.), (2007). Buenos Aires Gallega. Inmigración, pasado y presente. Comisión para la preservación del patrimonio histórico cultural de la ciudad de Buenos Aires. Buenos Aires. P. 19-22.

(2011). "El asociacionismo gallego en Buenos Aires y las posibilidades que ofrece para el estudio de la integración de los migrantes: un análisis a partir del archivo de la FAGA-MEGA". En: Antiteses, vol. 4, n 7, p. 151-171, en línea: Programa de Pós-Graduação em História Social da Universidade Estadual de Londrina. Recuperada el 12 de marzo de 2016 de http://goo.gl/tGL0kA. doi: 10.5433/1984$3356.2011 \mathrm{v} 4 \mathrm{n} 7 \mathrm{p} 151$

Galicia emigrante, $\mathrm{n}^{\circ} 1$, junio 1954 (Buenos Aires).

Galicia emigrante, $\mathrm{n}^{\circ}$ 4, septiembre 1954 (Buenos Aires).

GONZÁLEZ FERNÁNDEZ, H. (1994). Luís Seoane, vida e obra. Vigo: Galaxia.

La Opinón gallega, septiembre de 1946, (Buenos Aires).

GONZÁLEZ NEIRA, A (2010). Prensa del exilio republicano 1936-1937. Santiago: Andavira Editora.

LONGO FORMOSO, M. (1990). Cornide y la expedición de familias al Río de la Plata (1778-1984). A Coruña : Conterprint.

LÓPEZ CONDE, P. (1994) “América en el Archivo del Reino de Galicia”.En: Boletín de la $A N A B A D$, vol. 44, $\mathrm{n}^{\circ} 4$, Madrid : Confederación de Asociaciones de Archiveros, Bibliotecarios, Museólogos y Documentalistas. p.55-73.

LORENZO ALCALÁ, M. (2009). "Xavier Boveda: el 'ultraista' español que vivió entre nosotros". En: El catoblepas Revista crítica del presente.. № 8,[en línea] Fundación Gustavo Bueno, P. 14. Recuperado el 30 de abril de 2016 de http://goo. $\mathrm{gl} / \mathrm{LkSXd6}$

MEJÍA RUÍZ, C. (2011). Dos vidas y un exilio: Ramón de Valenzuela y María Victoria Villaverde: estudio y antología. Madrid: Universidad Complutense.

MONTES FERNÁNDEZ, F.J. (1988). Los orígenes de la radiodifusión exterior de España. Madrid: RTVE.

NEIRA VILAS, X. (1985). A prensa galega en Cuba. Sada: Edicións O Castro. (2001). A cultura galega en Buenos Aires: 1950- 1960. Discurso lido o día 17 de novembro de 2001, no acto da súa recepción. A Coruña : Real Academia Galega.

NÚÑEZ SEIXAS, X. M. (2011). "Deconstruyendo la parroquia 'glocal': asociacionismo, redes sociales y hábitat urbano de los inmigrantes gallegos en Buenos Aires (1900-1930)". En: Historia Social, nº70, Fundación Instituto de Historia Social. P. 107-133.

ORTIZ SOBRINO, M. A. (2013). "De la propaganda franquista a la Marca España 70 años de Radio Exterior". En: Historia y Comunicación Social, nº18 (OC). P. 219-230. en línea: Universidad Complutense de Madrid. Recuperada el 25 de mayo de $2016 \mathrm{de} \mathrm{http://goo.gl/UeEuLu.}$

OROZCO GALINDO, J. (2009). Radio Nacional de España. Nacida para ganar una guerra. Madrid: Manuscritos.

PALMÁS CASAL, R. (1978). A emigración galega na Arxentina. Sada: Edicións O Castro. 
PAMIÈS, T. (1999). "Emisiones en onda corta. La radio en el exilio". En: BALSEBRE, A. (Coord.), En el aire. 75 años de Radio en España. Madrid: Cadena Ser. PÉREZ, J. y PÉREZ, G. (2009). "Aspectos relevantes de la comunicación radiofónica de los emigrantes con sus comunidades". Documento del Segundo Foro Internacional de Derechos Humanos y Tecnologías de la Información y la Comunicación en la Educación. Ciudad de México: Instituto Politécnico Nacional, CFIE. Recuperado el 30 de enero de 2016 de http://goo.gl/4ayqCm

PÉREZ PAIS, M.C. (1986). "La prensa de la emigración: análisis y valoración ". En: DE JUANA, J y CASTRO, J. (Eds.), (1986). Sociedade e movemento obreiro en Galicia. Ourense: Deputación provincial de Ourense.

PÉREZ RODRÍGUEZ, L.(1996). Fernando Iglesias "Tacholas". Un actor auriense na Galicia Ideal. Sada: Edicións O Castro.

PIÑEIRO-OTERO, T. y COFRADES, M. A. (2016). "El papel de la radio en la emigración. Una aproximación desde la colectividad gallega en Argentina". Comunicación presentada al Congreso de Creación Intelectual celebrado en mayo de 2016 en Caracas: Universidad Metropolitana.

PORTEIRO, M.X. y TORRES BUGALLO, V. (2012). "Maruxa Boga. Voz e memoria da Galicia transterrada en Arxentina". En: Álbum de mulleres, Consello da Cultura Galega [En línea]. Recuperado el 30 de marzo de 2016 de http://goo.gl/ gGgDdr .

REBOLO VÁZQUEZ, M. (2002). Bos días, galegos: eiquí sempre en Galiza. Santiago de Compostela: Laiovento.

(2008). "A voz do exterior. A radio galega máis sentida". En: Grial, nº 180. Galaxia: Vigo. P. 46-51.

(2011). "A voz de Galicia fóra de Galicia. A Radio exterior" En: RODRÍGUEZ, M. (Coord.), (2011). Galicia pola radio. A historia Falada 1933-2008. Santiago de Compostela: Bolanda. P.43-57.

REY CASTELAO, O. (2001) "Los gallegos en el Río de la Plata durante la Época Colonial”. En: NÚÑ̃Z SEIXAS, M. (Ed.) (1991). La Galicia Austral. La inmigración gallega en Argentina. Buenos Aires : Biblos. P. 23-53.

(2013). "Del: oportunidades y medios de fraude y de corrupción". En: Spania. Revue interdisciplinaire dètudes hispaniques médiévales et modernes, $\mathrm{n}^{\circ} 16$, en línea: Civilisations et Littératures d'Espagne et d'Amérique. doi:10.4000/e-spania. 22854

ROCA, S. (2011). "Nosotros emigrantes. Estereotipo de la diáspora gallega en el cine argentino". En: Actas IV Congreso Intenacional Latina de Comunicaión Social. La Laguna: Universidad de La Laguna.

RODRÍGUEZ, E. (1994). Matádeo mañá. Vigo: Xerais.

RODRÍGUEZ, M. (Coord.), (2011). Galicia pola radio. A historia Falada 19332008. Santiago de Compostela: Bolanda.

SAMUELLE LAMELA, C. (2000). La emigración gallega al río de La Plata. Santiago de Compostela: Xunta de Galicia.

SIMÓN PALMER, C. (1991). Escritoras españolas del siglo XIX. Manual bio-bibliográfico. Madrid: Castalia. 
SOTO, M. (2003). "Republicanas" En: Página 12, viernes 28 de febrero [En línea]. Recuperado el 30 de marzo de 2016 de http://goo.gl/QmGPR7

SUÁREZ, R. (2011). "Biografía ofrecida por Ramón Suárez 'O Muxo', en su programa 'Con Vos', Radio cultura, 97.9mh, emitido el día en el que día en el que Maruxa Boga cumpliría los 95 años (marzo 2011)". En: Álbum de mulleres, Consello da Cultura Galega [En línea]. Recuperado el 30 de marzo de 2016 de http://goo.gl/azGgU9.

VILANOVA RODRIGUEZ, A. (1957). Los gallegos en La Argentina. Buenos Aires: Ediciones Galicia. Vol. I y II.

WESTOWOOD, S. y PHIZACLEA, M. (2000). Trans-Nationalism and thePolitics of Belonging. Londres: Routledge.

\section{Notas}

1 El presente trabajo se efectuó durante una estancia en Buenos Aires, financiada por el Banco Santander. Asimismo este trabajo no sería posible sin la colaboración de Dr. Ruy Farías, Museo de la Emigración Gallega, Asociación de la Prensa Española en Argentina, Federación de Asociaciones Gallegas de la República Argentina, Centro Galicia, el Colegio Santiago Apóstol, Terzo da Fala, Círculo Social Valle Miñor; de los conductores y equipos de los programas Galiza Emigrante, Un Canto a Galicia, Galicia con Vos, Caminando por España y en general de todas aquellas personas y entidades que nos orientaron en nuestro camino.

2 La denominada Expedición de las familias fue un proyecto para poblar la Patagonia con familias gallegas "bien instruidas en todas las labores del campo y otras faenas correspondientes a la mejor enseñanza de cosas domésticas" aprovechando el tráfico de buques-correo entre A Coruña y América. Este proyecto se inició por una real orden del 22 de junio de 1778 dirigida por el entonces ministro de marina, José de Gálvez, al Intendente de Galicia, Jorge Astraudi. Cfr. Rey Castelao (2001), Longo Formoso (1990)).

3 Siguiendo datos de Eiras Roel (1992, 185 y ss.) el número de españoles que embarcaron hacia América pasó de 315.068 individuos en el período de 1861-1880a 2.259.832 individuos entre 1901-1920.

4 En 1914 vivían en Buenos Aires unos 150.000 gallegos mientras que en A Coruña, en aquel momento la urbe más poblada de Galicia, apenas llegaban a 60.000 (Farías, 2011:152).

5 Reproducción de una publicación de la emigración (sin datar) en la que se recoge la transcripción del editorial "Ser gallego" de la audición Radial Recordando a Galicia. En Rodríguez, M. (Coord.), (2011). Galicia pola radio. A historia Falada 1933-2008. Bolanda: Santiago de Compostela. P. 46

6 A pesar de que en su Historia da radio en Galicia (1999) Blanco Campaña destaca el éxito de esta primera transmisión intercontinental, atendiendo a la prensa del momento ( $C f r$. p. 142 y ss.), Blanco Rosas (2014) recupera algún artículo en el que se señala el posible fracaso de esta conexión debido a cuestiones tecnológicas.

7 Pérez Pais (1986) recoge un total de 208 publicaciones de la colectividad gallega en América: 108 en Argentina, 53 en Cuba y 47 en otros países. Blanco Campaña (1995) amplía ese número a 310 cabeceras, en su mayoría de la esfera rioplatense y antillana. 
8 Tercera época en el exilio del histórico periódico gallego fundado en 1907, órgano de expresión de las Irmandades da Fala (1916-1932) -organización política y cultural de corte nacionalista- y del Partido Galeguista (1932-1936).

9 A partir de 1936 el llamado Bando Nacional o Franquista, consciente de las potencialidades de la radio para la propaganda, empezó a emitir partes de guerra para informar a América y Europa. Esta información fue derivando hacia una breve programación que combinaba contenidos musicales con información que transmitía el entusiasmo de la verdadera España. Estas retransmisiones se iniciaron en la emisora Tablero de Tenerife para, posteriormente, en 1937 centralizarse en Salamanca (Montes Fernández, 1930 y ss.; Orozco Galindo, 2009:249).

10 Siguiendo a Piñeiro-Otero y Encina (2016) en agosto de 2015 había tres audiciones radiales en antena en diversas emisoras de la capital porteña: Un canto a Galicia de Javier Lence; Galicia con vos de Ramón Suárez el Muxo y Galiza Emigrante de la Federación de Asociaciones Gallegas de la República Argentina con Francisco Lores, además de una iniciativa de webradio en el Círculo Social Val Miñor de Galicia en Buenos Aires. 